\author{
Pius W. Akumbu \\ University of Hamburg
}

\title{
Reflections on a community-based approach to writing grammars of endangered African languages
}

\begin{abstract}
Increasingly, there have been proposals for grammar writers to take into account the realities and needs of the community in order to produce grammars that can serve the interests of the native speakers (e.g. Kadanya 2006, Rehg 2014). Obviously, a grammar of an endangered language should, among other things, lead to the maintenance and/or revitalization of the language. However, grammars that are comprehensive and clear (Noonan 2007, Payne 2014, Rice 2006), and yet focus on and meet the needs of the target community, are still rare. This paper provides a reflection, from a community linguist's perspective, on how a community-based grammar could be conceived and written in the African context. It is based on an exploration of grammars written by native and non-native speakers, as well as on the feedback from native speakers. The paper points out some practical challenges involved (e.g. with data collection, and actual use of the grammars), and upholds that a grammar that is based on community mobilization, sensitization, and training requires a greater involvement and follow-up by the grammar writer, especially after publication.
\end{abstract}

Keywords: grammars, endangered languages, community-based, reflections

\section{Introduction}

As I have said elsewhere, "if linguistic research on endangered languages does not arouse interest in maintenance and/or revitalization, or if research outputs 
do not actually reach the target language community, then the research has only been completed partially" (Akumbu 2018: 266). This is exactly what happens when publications end up in book-shelves and, at best, stimulate further investigations and promote knowledge in the scientific world. Many proposals for grammar writers to take into account the realities and needs of the community in order to produce grammars that can serve the interest of the native speakers have been made (e.g. Kadanya 2006, Rehg 2014). Ideally, the goal of a grammar writer should be to produce a grammar that is maximally useful to both linguists and speakers, now and in the future. In other words, a grammar of an endangered language should be accessible to speakers of the target language. Rehg (2014: 61) points out that a "community grammar, as described by Michael Noonan (n.d.), is a kind of reference grammar created for, and sometimes by, members of a linguistic community as an aid to establishing [or reestablishing] a language in the schools, for teaching the language to adults, [etc.]".

Efforts to slow down and counter language endangerment have increased tremendously over the last two to three decades with intensified funding for language documentation and an expansion of language description. More grammars have emerged as products of language documentation efforts and many have revitalization as their ultimate goal. However, grammars that are comprehensive and clear (Noonan 2007, Payne 2014, Rice 2006), and yet focus on and meet the needs of the target community, are still rare. This paper provides a reflection, from a community linguist's perspective, on how a community-based grammar could be conceived and written in the African context. I do not focus on why we should write such grammars because this has been properly discussed by others (e.g. Kadanya 2007). The issue I wish to consider is how we can work on grammar in such a way that it might be useful to the community of native speakers about which we write. I do not dwell on the standards of the grammars but focus on the method and activities that could lead to a grammar that is accepted and taken for their own by the community of speakers with whom and for whom the grammar is conceived and written. Some questions I hope to answer are the following: How can such a grammar promote the maintenance or revitalization of the language? How can it do more than just preservation? Is there a way to plan and write the grammar to achieve this goal? Is there something that can be included in the process intended to meet this objective?

This study is based on an exploration of stated goals of the existing grammars written by native and non-native speakers presented in section 2 , as well as on feedback from native speakers given in section 3. I go further in section 4 to point out that a grammar that is based on community mobilization, sensitization, 
and training requires a greater involvement and follow-up by the grammar writer, especially after publication. Finally, I provide some concluding remarks in section 5.

\section{Review of the existing grammars}

Several proposals (Black \& Black 2012, Kadanya 2006, Mithun 2006, Noonan 2007, Rehg 2014, etc.) have been made for grammar writers to consider the community of speakers and to design grammars that can serve the needs of the language users in one of several ways such as promoting the maintenance or revitalization of the language, facilitating the development of literacy materials, etc. I set out to verify whether such grammars exist and whether they are meeting the needs of their respective communities. I begin in this part by looking through grammars of some endangered Cameroonian languages to understand what their stated goals were at the time of writing. First, I consider grammars written by native speaker linguists, and then those written by non-native speakers. I draw mostly on grammars of Grassfields Bantu languages with which I am most familiar.

Tamanji (2009: 5) announces that the descriptive apparatus he uses in the grammar of Bafut, a Ngemba language of Northwest Cameroon, stays clear of any formal model of linguistic analysis and only provides a very simple straightforward description of the facts as they appear to him. His intention "is to make the description as simple as possible in order to make the book accessible to all categories of language practitioners who are interested in the Bafut language and in related Grassfields Bantu languages".

On their part, Akumbu \& Chibaka (2012: 9)1 point out that "without using any specific formal model, they provide a description of the grammar of Babanki, a Central Ring Grassfields Bantu language of Northwest Cameroon, in a way that it will be useful to the learners and teachers of the language, as well as to others interested in this and other Grassfields Bantu languages".

In their grammar of Oku, a Central Ring Grassfields Bantu language of Northwest Cameroon, Nforbi \& Ngum (2009: 19) ${ }^{2}$ express the desire that their work will "contribute to implementing government policy in the domain of mother-tongue education as it facilitates the teaching of Oku grammar. Though dedicated to

\footnotetext{
1 Pius Akumbu is a native speaker of Babanki.
}

2 Peter Ngum is a native speaker of Oku. 
the linguists and the Oku people, we hope that everybody will find pleasure in discovering the richness of African languages through the Oku language".

In his preface to the grammar of Bangwa, a Grassfields language of West Cameroon, Nguendjio (2014: IV) states that "as I was writing this book, I was worried by the fact that it would not serve the community because it is full of linguistic jargon which makes it inaccessible to a layman".

Lacking in these brief statements by linguists writing grammars of their mother tongues is a clear indication of the usefulness of the grammar to the community of speakers. Of particular interest is the fact that these authors are also members of their respective communities. In some cases, attempts are made to stay clear of theoretical complexities in order to make the grammar accessible, but at the bottom of it all the researchers are out to satisfy the requirements of their respective universities that expect them to publish high quality work (abroad) and also in some cases to satisfy their funding agencies. Some grammars are written just to fulfil the requirements of the educational system and earn a degree. This strategy leads the community members to work on the language for their individual benefit rather than for the benefit of the community. This probably explains why there is no commitment on the part of the authors to follow up the consumption of their grammar nor the general development and use of the language. After publication, the authors consider their task complete and move on to a different issue of inquiry or simply continue with their job at the university and rarely have anything to do with the development of the language. In the places where language development committees exist, a linguist is sometimes seen as a threat and there is hardly any cooperation between the committee members and the linguist.

Also, worth mentioning is the fact that in most cases, the data is the author's idiolect that is verified by one or two other speakers, and may not be considered as a proper representation of the entire community. Tamanji (2009: 6) in his acknowledgements appreciates a single community member who "was very instrumental in crosschecking my Bafut data especially as concerns the transcription of tones". Akumbu \& Chibaka (2012: XIII) declare that "most of the data used in this book was gathered by the first author [...]". Nforbi \& Ngum acknowledge the Oku Language Committee and the Cameroon Association for Bible Translation and Literacy (CABTAL) ${ }^{3}$ team in Oku for their collaboration. They equally list

3 CABTAL was officially established in 1987 to work with local Cameroonian communities to translate the Bible into their languages and to run literacy classes to prepare the people to read and write those languages in order to make use of the Holy Scripture. 
three other consultants who helped in providing the data for them to analyze, and emphasize that "these informants are just a representation of the many Oku speakers who assisted" (Nforbi \& Ngum 2009: 9). Nguendjio (2014), on his part, is mute on the sources of the data he uses in the grammar of Bangwa.

Next, I consider grammars written by the non-native speakers. Talking about Obang, a Ngemba language of Northwest Cameroon, Asohsi (2015: 10) states her "passion to describe and document a tongue that can someday serve educational purposes in schools and also in the local churches within the community". She further mentions that her aim is "to provide reliable data by letting the language tell its story with simple linguistic descriptions from a structural and typological perspective that can be useful for descriptive or documentary, comparative, theoretical linguists as well as to a wider audience".

Atindogbe (2013) hopes that the absence of a sophisticated linguistic jargon will make his short version of the Mokpe (a Coastal Bantu language of Southwest Cameroon) grammar also accessible to non-linguist readers. "I am thinking, first and foremost, about the Bakweri children who are no longer speaking their language due to the exclusive reign of Cameroon Pidgin English as an unavoidable Lingua Franca of the Southwest Region, as well as English and French as the two official languages of Cameroon". Furthermore, he expresses the desire that Mokpe students studying linguistics "can now see how their language functions and accommodates phonological processes such as assimilation, deletion, tone copying, etc. notions that look so unfamiliar and so abstract to them although they practice them in their everyday use of their mother tongue". He also wishes that the authors who have attempted to provide an alphabet and orthographic rules to read and write Mokpe will find the grammar useful and an inspiration to solve the problem of harmonization of the alphabets. Considering that many alphabets will not ease the reading and learning process he expects that one writing system will be adopted even if it will undergo adjustment in the future. He finally wishes that the Bakweri people who are "struggling" to have their language and culture known by the children and the general public will find the grammar a useful tool.

This category of grammars seems to involve the community although it can be seen that only a few individuals are involved in the data collection process. Atindogbe (2013: 4), for example, acknowledges "my 'many-in-one' consultant who understood at the early stage of this work my intention and gave me all the linguistic support. His role did not only consist of kindly providing data for the book but also to explain and research on the areas or questions he could not answer immediately during our elicitation sessions". 
The grammar of Mundabli, a Lower Fungom language of Northwest Cameroon (Voll 2017) is based on recordings made during three field trips to Cameroon totalling a period of 9 months. During these trips, the author made recordings in Mundabli village as well as in the neighbouring towns and worked with several consultants. She explains that "recordings of spontaneous speech were transcribed and glossed with the help of consultants". Unfortunately, she doesn't say how this grammar will serve the needs of the Mundabli people. This is similar to Lovegren (2013: 7-13) who presents the setting of data collection for the grammar of Mungbam, a Lower Fungom language of Northwest Cameroon, and acknowledges all the consultants who helped in various ways but doesn't say how the grammar might be useful to the people. The grammar of Kutep, a Jukunoid language of East-Central Nigeria "is intended to make a contribution towards closing the breach by presenting a sketch of basic phonological, morphological, and syntactic patterns in Kuteb, one of the 150 or so languages of the Central Nigerian group within the (East) Benue-Congo family" (Koops 2009: 1). The author further states that the sentences are, in most cases, taken from the tape-recorded texts produced by some consultants and that the tape-recorded examples were used to elicit other sentences. Finally, he says that "Mr. Obadiial Abomei has been very helpful in checking the naturalness of all the sentences in this work" (Koops 2009: 14). This shows that nothing is explicitly said about the usefulness of the grammar to the native speakers.

Again, it is evident that the writers of these grammars are primarily concerned with their academic pursuits rather than focused on language development for the interest of the community. Like in the case of native speaker linguists, their engagement ends once the grammar is published, unless there are more linguistic intricacies to explore. This is certainly the case for most grammars written by academic linguists who, at best, express a wish for the community to benefit from their grammar but do not design and implement any measures for further exploitation of their work. Talking about the limitations of their grammar, Crane, Hyman \& Tukumu (2011: 6) point out that "as indicated in \$1.1, it is our sincere hope that this Nzadi (a Bantu language of the Democratic Republic of the Congo) grammar will be of use to scholars of different sorts, and ultimately to the Nzadi community as well (although this might better have necessitated a version of the grammar in French)". To make the point clearer, they provide a list of limitations and the steps they took to mitigate their effect on the study:

(i) We have been able to work with only one speaker. Ideally, we would have liked to work with several, particularly as we found variation in a number of places in the grammar (e.g. in the tone of the past tense proclitic /ó/, realized 
variously as $\mathrm{H}, \mathrm{HL}$ and $\mathrm{L}$ ). Because of this limitation we cannot tell if the inconsistencies we observed derive from systematic differences between dialects or age groups, or if they represent free or idiolectal variation. Where we have detected variation, we have noted this in the relevant section of the grammar.

(ii) Most of our information has come from elicitation rather than from direct observation of speakers using the language. We have tried to overcome this in part by collecting narratives, but this does not show how speakers exploit Nzadi in interactional situations.

(iii) Related to this, we have done the study in Berkeley, not in Nzadi country, and we have worked in translation rather than through the first language (Crane, Hyman \& Tukumu 2011: 6).

Many linguists are most likely to encounter most or all of these problems and their grammars might not be able to meet the needs of the community.

Another set of grammars I wish to explore is that written by missionaries affiliated to either SIL International Cameroon ${ }^{4}$ or to CABTAL. The leading principle at the two organizations is that literacy and Bible translation must be locally owned and locally driven because such an approach fosters sustainable community development. Work by missionary linguists has come under criticism (Dobrin \& Good 2009, Grenoble \& Whaley 2005, Handman 2009, Keane 2002, Pennycook \& Makoni 2005, Rehg 2004), but my interest is on how they aspire to serve the community of speakers.

Hedinger (2008: 1) indicates that his description of the grammar of Akoose, Bakossi, Bantu A.15b, Southwest Cameroon, "is intended for a wide audience, both linguists and non-linguists, speakers and non-speakers alike. I have therefore tried to use non-technical language as much as possible while at the same time giving a linguistically sound description of the facts of the language".

Writing about the grammar of Buwal, a Chadic language of Far North Cameroon, Viljeon (2013: 21) states that:

4 Formerly called the Summer Institute of Linguistics, SIL International is a non-profit, scientific educational organization of Christian volunteers that specializes in serving the lesser-known language communities of the world. They further focus on the application of linguistic research to the literacy and translation needs of the minority language communities. SIL Cameroon (www.silcam.org) came into existence in 1967 and since then has worked on more than 130 Cameroonian languages. 
The aim of the project has been to train and equip local people as far as possible in the skills that they need to manage the development of their own language, with the SIL members moving more and more into an advisory role. With this view in mind, the community was encouraged early on to form a language committee to oversee the work. Major decisions on the orthography were made by this group and this committee currently organizes the literacy efforts and the sale of books in the Buwal language. Later, a committee of church leaders was formed to oversee the work of Bible translation.

She affirms that this first detailed description of the language would "prove of great interest to academic linguists. Furthermore, my hope is that this work will assist the Buwal people in their efforts in developing and preserving their language and culture and that the recognition of their unique identity will give them confidence in finding their place in an increasingly globalized world" (Viljeon 2013: 1).

These statements suggest that the linguistic work, including the writing of grammars, that the SIL missionaries undertake is intended to serve the community of speakers in some ways. This is reflected in the way the data is collected and in the extent to which community members are engaged in the process.

Viljeon (2013) reveals that the language data on which her study is based was collected over a period of roughly five years between 2004 and 2011. The author lived in the community for most of those years and worked with several people there. She writes:

Different types of language data were collected such as (i) lexical items (from natural texts, participant observation and language sessions), (ii) elicited examples (Often an example of a particular structure based on natural texts or observation was given to the informant and he or she was asked to provide similar examples. Direct translation was avoided as much as possible. Informants were questioned at times concerning their intuitions about the language, what can or cannot be said and in which types of situations certain utterances may be said), and (iii) natural texts (Ninety-nine natural texts of varying lengths and genres have been collected. The majority of these were recorded and then transcribed. However, six of the texts were written by native speakers to put in a book for those learning to read the language. Although many of the texts came from regular language informants, a significant number were provided by other members of the community, the majority being from Gadala Centre) (Viljeon 2013: 22-23).

In order to write the grammar of Akoose (2008), Hedinger (spent more than 25 years collecting data from the community ${ }^{5}$. Many of those years were spent

5 Personal communication. 
learning the language and culture of the Bakossi people and training several members of the community on several aspects of linguistics, including basic literacy skills, text collection methods, etc.

To write the grammar of Nchane, Northwest Cameroon, Boutwell (2010) collected a number of texts of various genres. He also used elicited sentences and words collected over a period of four years, from 2006 to 2009, while living in the village of Nfume, with the help of several language consultants.

In 2014 Boutwell wrote A sketch grammar of Mungong language of Northwest Cameroon, with data derived primarily from a number of Mungong narrative texts, as well as from elicited sentences and words collected over a period of seven years, from 2007 to 2014. He further specifies that "significant data collection and analysis was accomplished as a result of a series of grammar workshops held in Misaje in late 2012. The texts and other language data were collected with the help of several language consultants, most notably Kemcha Gabriel, Nganti Joseph, Ngong Augustine, Sofa Cletus, Ferdinand Muchuo and San Linus Gabushi" (Boutwell 2014: 2).

In a similar manner, McLean (2014) used data from a number of Central Mfumte texts from a range of genres and elicited utterances to write the grammar of Mfumte, another language of Northwest Cameroon. According to him, "these texts and utterances have been gathered over a period of five years, from 2008 to 2013. The texts and other language data were collected with the help of several Central Mfumte speakers, especially Mr. Detoh Frederick and Pastor Nwufa William".

The next fundamental issue to consider is the extent to which the hopes and wishes of the authors presented in this section have actually been materialized.

\section{Realization of the goals of the existing grammars}

As illustrated in the preceding section, most writers of grammars would like to see their work contribute to a better understanding of the language, ensure its maintenance or preservation, lead to the revitalization of the language, act as a resource for its further development, etc. To know whether these goals are being attained, it was necessary to verify it with community members. Four main issues that were considered are 1) awareness of the existence of the grammar, 2) availability of the grammar, 3) ability to read the grammar, and 4) necessity of the grammar. Questionnaires were administered and interviews were conducted with speakers of languages known to have grammars. For each grammar 
evaluated, an effort was made, using my social networks, to get responses from people with formal education, living out of the community (50 per language) and those living in the community (25 per language), as well as those without formal education, living out of the community (25 per language) and those living in the community (50 per language). Five languages were targeted, including three Grassfields Bantu languages of Northwest Cameroon (Babanki, Bafut and $\mathrm{Oku}$ ) and two Coastal Bantu languages of Southwest Cameroon (Mokpe and Akoose). The total population of these five communities is 346,000 (Eberhard, Simons \& Fennig 2019) but responses were obtained only from 750 respondents. This was partly due to time constraints as well as the political crisis in Cameroon that started in 2016 and was still going on in 2018 when the data were collected.

\subsection{Awareness of the existence of the grammar}

Responses from the questionnaires and interviews reveal that even though the grammars of the languages were published several years ago (Akoose - Hedinger (2008); Babanki - Akumbu \& Chibaka (2012); Bafut - Tamanji (2009); Mokpe Atindogbe (2013); and Oku - Nforbi \& Ngum (2009)), most native speakers are unaware of their existence. Only Akoose had up to 44\% (66) of 150 people who said they knew that a grammar of their language has been written. It should be noted that either SIL Cameroon or CABTAL is involved in literacy development and/or Bible translation work in these five communities. However, the involvement in Akoose has been greater and has been going on for more than three decades. Another reason for this awareness is probably the fact that like with the Zapotec grammar (Black \& Black 2012: 106) there was a large celebration of Akoose grammar but not that of the other languages. This probably explains why the Akoose community members are aware of the linguistic work on the language. The number of respondents who knew that a grammar of their language exists was 28\% (42) in Bafut where SIL Cameroon and CABTAL have also been involved for more than three decades. The responses are presented in Table 1.

TABLE 1. Awareness of the existence of the grammar

\begin{tabular}{l|c|c|c|c|c|c|c}
\hline & Oku & Babanki & Mokpe & Bafut & Akoose & Total & $\%$ \\
\hline No grammar & 122 & 120 & 74 & 80 & 48 & 444 & 59.3 \\
\hline Unaware & 22 & 24 & 68 & 28 & 36 & 178 & 23.7 \\
\hline Aware & 6 & 6 & 8 & 42 & 66 & 128 & 17 \\
\hline Total & 150 & 150 & 150 & 150 & 150 & 750 & 100 \\
\hline
\end{tabular}


Out of the 150 Oku respondents, $81.40 \%$ (122) said there is no grammar written on the language, $14.60 \%$ (22) said they were not aware, and only $4 \%$ (6) said there is one. The responses about Babanki were as follows: $80 \%$ (120) said there is no grammar book on the language, $16 \%$ (24) said they didn't know, and only $4 \%$ (6) said there is one. $49.30 \%$ (74) Mokpe respondents said there is no grammar written on the language, $45.30 \%$ (68) said they did not know, and $5.40 \%$ (8) said there is a grammar. Bafut speakers responded as follows: $53.40 \%$ (80) said there is no grammar, $18.60 \%$ (28) did not know, and $28 \%$ (42) said there is a grammar. The results on Akoose were as follows: $32 \%$ (48) said there is no grammar on the language, $24 \%$ (36) said they were not aware, and $44 \%$ (66) said they were aware that a grammar of the language has been written. The chart presented in Fig. 1 gives a graphical view of the degree of awareness of the existence of the grammar among native speakers.

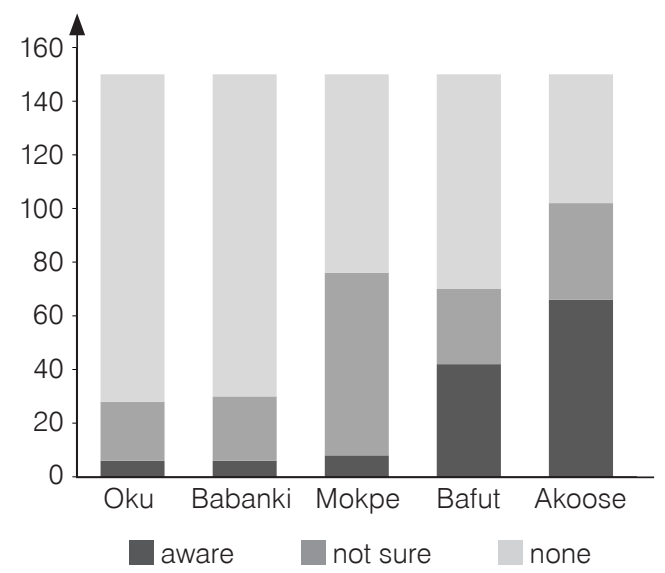

Fig. 1. Awareness of the existence of the grammar

The results equally point to the fact that in most cases, academic linguists write grammars for their professional interest, not for the benefit of the community. Due to the academic and professional responsibilities of the academic linguist, their engagement generally ends as soon as the grammar is completed or published. A suggestion that can be made here is that while researchers conduct research, publish, and archive their findings, they should figure out ways to disseminate the results, i.e., take them back to the people of the study area. In section 4 , it is shown that this is best done by involving community members in the process of writing a grammar. The community members can then ensure the continuity and sustainability of work on the language. 


\subsection{Availability of the grammar}

The other issue that was considered was the availability of the grammars. If a grammar is to serve the community of speakers, it should be available to them. Those who said they were aware of its existence were asked whether they own a copy. Unfortunately, a majority of the respondents in the five communities did not have a copy of the grammar. During interview sessions, a few people said they had seen such a book but didn't have it. Table 2 shows the number of respondents who have copies of the grammar of each language.

TABLE 2. Availability of the grammar

\begin{tabular}{l|c|c|c|c|c|c|c}
\hline & Oku & Babanki & Mokpe & Bafut & Akoose & Total & $\%$ \\
\hline Have & 2 & 1 & 2 & 2 & 6 & 13 & 10.2 \\
\hline Do not have & 4 & 5 & 6 & 40 & 60 & 115 & 89.8 \\
\hline Total & 6 & 6 & 8 & 42 & 66 & 128 & 100 \\
\hline
\end{tabular}

In Oku, 33\% (2) out of 6 respondents had a copy of the grammar. Only 16\% (1) of 6 Babanki respondents had a copy of the Babanki grammar (given to them by the author) and 25\% (2) of the 8 Mokpe respondents owned copies of the grammar (also given to them by the author). Meanwhile only $4 \%$ (2) out of 42 Bafut respondents said they owned a copy and 9\% (6) out of 66 Akoose respondents who knew about the grammar said they owned a copy. These facts are illustrated by the graph in Fig. 2.

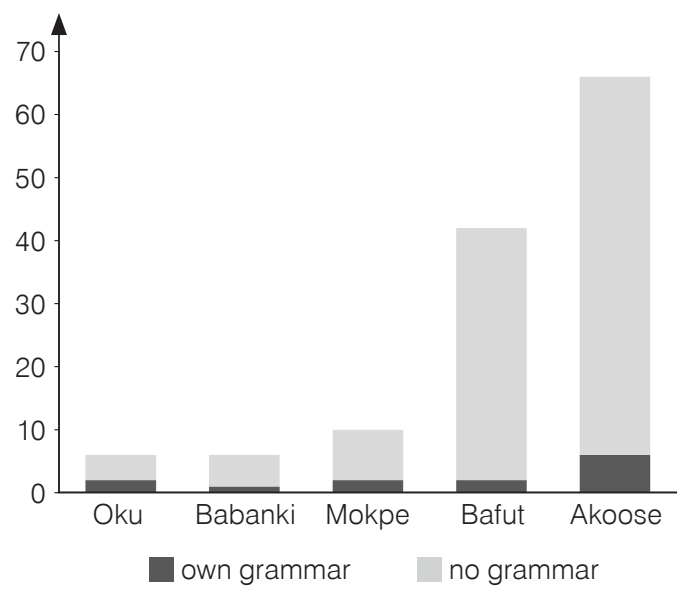

Fig. 2. Availability of the grammar 
There can be several reasons for the unavailability of the grammars, the main one being that most publications, especially those printed on the other continents, hardly reach Africa. Those that reach there are usually too costly for the local people. Talking about the Babanki grammar, Akumbu (2018: 271) says: "Even the grammar book published in Germany has not reached the Babanki community due to lack of information on its existence and the high cost. The thirty copies I received as an author from the publisher were insufficient for myself and my colleagues".

For the linguist, it is important to publish with a renowned publisher and most African universities require scholars to publish their work abroad. The Babanki (Akumbu \& Chibaka 2012) and Bafut (Tamanji 2009) grammars were published in Germany, the Mokpe grammar (Atindogbe 2013) in Japan, etc. This again reinforces the idea that in most cases, the academic linguists conducts research and publish mainly for their personal interest and to satisfy the needs of other linguists. The grammars are used by those who study languages but not by those who speak the languages. Furthermore, it should be mentioned that the cost of the grammar is relatively high for an African who has to depend on their private resources to buy a copy. Even if they had the money and were willing to spend it for a grammar book, they will have to deal with the challenge of ordering it online or getting someone to bring it along when they travel.

These challenges might be overcome if the community were involved in the grammar writing process. Even if the grammars were published abroad, the community could arrange printing and sale locally at lower, affordable prices.

\subsection{Ability to read the grammar}

Owning a grammar book is one thing, and using it is another. I sought to find out whether those who owned a copy of the grammar were able to read it or not. All the 13 respondents in the five communities who had copies of the grammar said they could read them but specified during the interviews that they needed a lot of training and practice with the symbols (alphabet) to be able to read. They complained mostly about the sounds, e.g. $\eta, \phi, \beta, 4, ?$, that are used in writing the Cameroonian languages but are not found in the English language they are familiar with. Another area of great difficulty is the use of tone marks on vowels. Most of the people find it extremely difficult to read these unfamiliar marks and would rather not have them there (cf. Bird (1999) for a similar report among the Yemba of Dschang in Cameroon). Kafeteh (2018) reports that Kom people of Northwest Cameroon do not often use mother tongue literature because 
they are not familiar with the materials. He argues that despite all the efforts made to advance literacy training in Kom, the literature reading rate remains surprisingly low.

The second reason for the inability to read the grammars which came out clearly during interviews is the fact that the people do not have a culture of reading. Most people with oral traditions would rather listen or watch instead of read. Sometimes, a linguist can think of giving to the community some copies of the grammar - but of what use would it be to people who in most cases are illiterate in the foreign language in which the grammar was written, and are also unable to read and write in their own language? Weighing the potential downside of introducing a grammar to a community with strong oral traditions, Guérin (2008: 62) suggests that it is most ethical for the linguist to follow the desires of the community. All the five communities presented in this analysis cultivate a living oral tradition and their motivation to read (either in English or in their community's language) is low. When a few people attempted to read, when they found out that the alphabet is complex, they easily gave up. One respondent said: "I really like to read and write my language but what is this and this? (pointing to a schwa and a velar nasal) [...] Why is this 'e' upside down?"

At least two things can be done to overcome this difficulty. First, it might be necessary to simplify the orthography as much as possible. The use of tone marks should be minimal and only where it is absolutely necessary. The unfamiliar symbols could also be avoided. However, if the community is involved from the initial stages of the grammar writing process and the symbols to be used agreed upon by the linguist and the community members, the chances of accepting them are higher. Secondly, since learning to read and write a language requires a lot of training, literacy classes could be organized during the grammar writing process or at a moment that is convenient to both parties. Even when this is done, the people have to be educated on why they need that knowledge. They need to be convinced that development is started and cultivated through literacy. When a person learns to read, their eyes are opened to a whole new world of possibilities and positive change can begin to take root. They gain the ability to facilitate change, rather than implement and be responsible for change. Mother tongue literacy transforms a culture, leading to the development of new skills and knowledge, fresh confidence, and the ability to function as full members of society (Chuo \& Walter 2011, UNESCO 2010). When a community catches the vision and its own dream, its development can remain long-term. 


\subsection{Necessity of the grammar}

One issue that people talked about during the interviews was the necessity to develop their languages. Many respondents wondered why it is necessary to have a grammar of an indigenous language, arguing that their language is not as useful as English, French or Cameroonian Pidgin English ${ }^{6}$. In reality, most families want their children to learn these global languages so as to be successful in future, ignoring the fact that children are more successful, even in English, when taught in their mother tongue (Chiatoh \& Akumbu 2014). Some people prefer the foreign languages for prestige and parents even take pride in having their children speaking Cameroonian Pidgin English, English, and some French. Even in the academic milieu in Cameroon the idea of developing and using indigenous languages for education and development has not gone unchallenged. Some argue that mother tongue education is a wild dream because it has no future in an age of rapid globalization, where world languages have a clear advantage over minority mother tongues. Attitudes towards national languages ${ }^{7}$ have been shaped by opinions which have given the false impression that national unity is only achievable through foreign languages. In this respect, Mono Ndjana (1981: 184) submits:

Les politiciens demandent le développement des langues nationales et l'alphabétisation dans ces langues [...] Je pense dans l'intérêt de la nation, il faut mieux ne pas souligner ce problème de langue nationale. L'anglais et le français ne nous aident pas mal à nous entendre déjà. C'est l'essentiel'.

In Mono Ndjana's view, the protection of national interest is best guaranteed through the use of English and French. Admittedly, it is not beneficial to bother about national languages since English and French already help Cameroonians to understand one another. Here the insinuation is that while English and French

6 English and French are the two official languages of Cameroon inherited from the colonial experience. English is the language of education and administration in the two Anglophone Regions of Cameroon, while French is used in the eight Francophone Regions of the country. Cameroon Pidgin is the language of wider communication in the entire Anglophone Cameroon as well as in some parts of Francophone Cameroon. It is also the language of trade and is commonly used in workplaces across Anglophone Cameroon.

7 I use national languages here to refer to the indigenous languages of Cameroon.

8 Politicians are requesting the development and use of national languages in education. [...] I think, in the interest of the nation, that this issue of national languages shouldn't be raised. English and French are already sufficient for us to understand each other. That's the essential thing. 
are integrators or unifiers, national languages are rather disintegrators and so should be avoided. A similar opinion is expressed by Bouba (1995) who is of the opinion that national languages are irrelevant in the Cameroonian context since even in the most remote areas, people speak and understand English and French, and that advocating for national languages means taking the country backwards to the moment when Cameroonians were starting to understand one another. Misleading as these views are, though, they have come to represent an ideal position within educated and non-educated circles and many people think that going straight for English or French is the best option.

Many interviewees recognized and agreed that their indigenous languages are important and useful in keeping them connected to their culture and, above all, in passing their cultural elements to future generations but did not quickly agree that through their own languages their children could have opportunities to learn better and faster and eventually have or create jobs, as well as excel in business. For these reasons the motivation to support the writing of grammars of indigenous languages is actually low in many parts of Cameroon.

As discussed in greater detail in the next section a grammar can be useful to the community only if there is sufficient sensitization. Community members need to understand the place and role of their language in the face of global languages. Only education and sensitization can induce interest and motivate many community members to initiate and run language development activities, including the writing of a grammar. Black \& Black (2012: 103) argue that indigenous people want to be involved as they are becoming more educated and more interested in working on their own languages.

\section{Community-based grammar}

In the previous section, a number of challenges that current grammars of some endangered indigenous languages face have been presented. It seems that part of the solution is to embark on writing community-based grammars. In this section, an attempt is made to describe what a community-based grammar is and how it can resolve the problems. It must be stated that "good" grammars are those that are comprehensive and clear, providing a proper coverage of structures of the language (Noonan 2007, Payne 2014, Rice 2006), yet focused on meeting the needs of the target community. The audience for a grammatical description should be taken into consideration by the writer. At the top of the list of users of a grammar should be members of the community in which the language is spoken. The success of any written communication is usually based 
on its reception and so writers always have their audiences in mind. Writers always want to know who will read what they write, as well as what their needs and expectations are. In the case of grammar, the audience can vary tremendously ranging from linguists to the community of speakers of the language concerned. The point is that a grammar should serve not only the linguists but also the target community audience. As Black \& Black (2012: 103) point out, a different type of grammar is needed: one that serves the language community, describes the language in general terms, and is also useful to linguists for extracting data for analysis. This type of grammar has the potential to revitalize the use of a language as the people realize their language is a "real" language worth of use because it has a grammar. Mosel (2006: 45) adds:

[...] grammarians should not only think about the design of grammars for linguists, but also develop strategies of how such grammars can be transformed into grammars for non-specialists. One of the problems to solve is, for instance, that the prospective users are not familiar with linguistic terminology, so the grammarian should keep scientific terminology to a minimum and explain every term he or she uses in simple words.

This places a burden on grammar writers who should have linguistics as a driving force, as well as the interests of the people at heart. The linguist is invited to make extra effort to help the community appreciate their own language and work to develop it. This effort is required to avoid 'mining' a local community for the grammar writers' benefit, "leaving the community of speakers with nothing" (Kadanya 2006: 253). There may be justification for the way linguists operate, but my position is that it is unfair for anyone to go to any given community, collect data, write a grammar, receive an academic or professional qualification, become a successful and renown linguist, with all kinds of benefits, while the community gets nothing of this ${ }^{9}$.

\subsection{What is a community-based grammar?}

The answer to this question requires a proper review and understanding of what Community-Based Research (CBR) is. This research model that emphasizes collaboration between linguists and language communities encourages research

9 While I make this critique, I recognize the fact that academic grammar writers who support the development of grammatical descriptions and also work with communities are doing hard work that many other linguists are not bothered to do. Many of them could become "famous" by abandoning all the efforts they make to secure grants and focus on theoretical work. 
on a language, conducted for, with, and by the language-speaking community within which the research takes place and which it affects. This kind of research involves a collaborative relationship between researchers and members of the community (Bischoff \& Jany 2018, Cameron et al. 1992, Czaykowska-Higgins 2009). It is community-based because a researcher joins his efforts with community members to carry out activities in that community for the benefit of both parties. CBR has become a valued model in linguistic research during recent years, particularly in the areas of language documentation and revitalization. According to Rice (2018: 15):

Community-based research begins with a research topic of practical relevance to the community and is carried out in community settings. Second, community members and researchers equitably share control of the research agenda through active and reciprocal involvement in the design, implementation, and dissemination. Finally, the process and results can transform and mobilize diverse ideas, resources, and experiences to generate positive action for communities.

According to Ochocka \& Janzen (2014), community-based research is community-driven (i.e., it begins with a research topic of practical relevance to the community and promotes community self-determination, participatory (i.e., community members and researchers equitably share control of the research agenda through active and reciprocal involvement in the research design, implementation and dissemination), and action-oriented. The goals of the researcher and community members must be clearly defined in order to establish a productive long-term collaboration in which both parties benefit from the interaction. Leonard \& Haynes (2010) stress the importance of collaborative consultation in defining research roles and goals. Ameka (2006: 70) insists that "unless the records of the languages being documented are the product of collaboration between trained native speaker and non-native speaker (anthropological) linguists, they will not be real, or optimal descriptions representing the realities of the languages".

A community-based grammar is, therefore, one that is written with community support or at the behest of the target language community (Lükpe 2011, Rehg 2004) but also appropriate for the linguistic community. One of the most important consequences of the community-driven approach is that participants (and the community at large) are more likely to embrace and take responsibility for the product that emerges.

Although writing such a grammar can face a number of challenges (cf. Rice 2018: 28-31), it remains a model for writers of grammars of endangered languages to adopt. What exactly is involved in this model is discussed next. 


\subsection{Writing community-based grammars: Reflections}

As I mentioned in section 2, several proposals have been made for grammar writers to consider the community of speakers and to design grammars that can serve the needs of the language users in one of several ways (Black \& Black 2012, Kadanya 2006, Mithun 2006, Noonan 2007, Rehg 2014, etc.). Some of the proposals encourage community mobilization, training, engagement, and follow up (cf. Dobrin 2008, Dobrin \& Berson 2011, Fitzgerald 2017, 2018, Genetti \& Siemens 2013, Grenoble \& Whitecloud 2014). If implemented in context appropriate ways these lofty measures will ensure that grammars which emerge will actually meet the needs of the language community. Such grammars will not only contribute to preserving the language but may also help in revitalization efforts. They may lead to the production of educational materials and can provoke further interest in the study of the language. However, it is necessary to reflect on how possible it is for a linguist or the grammar writer to engage in all of these activities and processes given the limited time and resources that are at their disposal.

First, it appears that the grammar writer can best appropriate the extensive community mobilization and training only within the context of language documentation projects or such kinds of funded projects that require extensive fieldwork in the community. These include projects that are funded for at least one to three years, e.g. Endangered Languages Documentation Programme grants, National Science Foundation grants, the German Research Foundation (DFG) grants, and The Netherlands Organisation for Scientific Research grants. Unfortunately, many grammars of endangered languages are based on the data collected by a researcher from a few individuals during short field trips of several weeks and then analyzed out of the community, probably to fulfil academic requirements and obtain a degree. This is the usual practice, for example in Cameroon, where students typically do not have any funding that could allow field work for extended periods. Many students who write grammar sketches of their mother tongues tend to rely on their idiolects and hardly return to their communities for data collection. Some of the grammars are written by native speaker linguists away from their communities (and countries), far away from other speakers, in the context of fellowships such as those granted by Fulbright, the Alexander von Humboldt Foundation, and the Commonwealth. In such circumstances it is hard to think of community mobilization, training, and engagement. What could possibly work would be engaging in sensitization, language development, and training by native speaker linguists, like myself, as often as they have the time and resources to work for their community. This could also include 
providing communities with copies of the grammar and any other publications and attempting to inspire people to develop interest in reading these materials and promoting the use of their language.

Another problem is with sensitization. When community members are encouraged to understand the place and usefulness of their native language in the current global village, the reality they see, e.g. the use of the colonial languages like English in education and for official purposes, is clearly a counterargument and it is extremely difficult to be convincing. As a Babanki speaker once said: "You don go learn your whiteman talk get your work, get your money, you don come here for fool me and my pikin dem" or "You have studied English and had a job and riches, and have come here to deceive me and my children". How can the local people be convinced when even the government policy doesn't help them to see any economic or educational value in their languages? ${ }^{10}$ This problem can be addressed if indigenous languages are recognized and given some official functions. Community linguists should join efforts to accelerate the implementation of policies that empower their languages.

Another issue to consider is the economic and financial benefits that community members who offer their time and skills expect to get. It is always difficult to find people who can be trained and who are willing to sacrifice their regular day-to-day activities (e.g. farming, and hunting) and engage fully in linguistic work. In general, this kind of work is temporary and people are sometimes reluctant because they wonder what the future will be like. Even when they commit themselves, it is usually for a season - the period during which they are not heavily involved in their regular activities. This makes the training and engagement irregular. I believe that while it is hard to provide permanent jobs for community members who engage in language documentation and description (e.g. of a grammar), the grammar writer should try to pay the committed individuals well enough so that they can be better motivated. This is important because people know that anyone who gets to their community to work on their language is doing it for financial or academic benefits. A grammar writer should therefore not expect the people to offer free services or to exchange their services for food and drinks only. However, this suggestion can only be useful within the framework of funded projects, not when a community linguist is using their limited personal resources, as it is often the case in most of Africa.

\footnotetext{
10 While most African countries have opted for language policies in favor of indigenous endangered languages, implementation has been timid in most cases. In Cameroon, for example, none of the more than 250 indigenous languages is used as a medium of instruction, as advocated in the country's language policy statements.
} 
One of the difficulties new teams or individuals face when they arrive in a community in many parts of Africa is the fact that other linguists had been there before $^{11}$. Community members still cry out about the previous researchers who got to the community, collected data and then disappeared. The people feel cheated and exploited and rightly so because the researcher only tried to satisfy their personal needs, not those of the community. In many such cases, the people want to be paid immediately for their effort. The linguist needs time to rebuild confidence and trust and to get the people to consider them differently. In most cases, giving gifts of various kinds, including financial compensation can reestablish a relationship and eventually build trust but the same feeling will be left when the linguist leaves. This is so because those gifts are given to only a few individuals who may not be available in future. The best thing is to consider leaving something tangible for the entire community if the resources permit. Concrete offers to a community such as the Pig for Pikin initiative of the KPAAM-CAM project in Lower Fungom ${ }^{12}$ and the water supply initiative implemented by the Beezen Language Documentation Project ${ }^{13}$ leave open doors for researchers into these communities.

Another thing to reflect on is the lack of electricity in many indigenous communities. This is a major drawback in this era of overwhelming advances in technological development. An extended stay in a community for mobilization and training require electricity supply. In most cases, training involves the use of information and communication technologies which need electricity to function. In many cases the linguist might punctuate their stay in the community with visits to a nearby town where they can have access to electricity supply. This must be factored into planning and executed as time and resources permit.

The final thing to discuss here is the ability to read existing grammars. As said earlier, the audience for which the grammar is written must be taken into consideration. It has also been shown that most African communities have an oral tradition and reading has continued to be a burden even in academic circles. How then does the grammar writer expect the people, most of whom have not had formal education in the foreign language in which the grammar is written, to learn to read (and write) their own language (written with some unusual symbols)?

\footnotetext{
11 The same challenge is faced even by the community members, like myself, who have followed the academic path and no longer live permanently in the community where the language is spoken.

12 https://ubwp.buffalo.edu/kpaamcam/research-communities [23.08.20]

13 https://www.aai.uni-hamburg.de/afrika/medien/beldop.pdf [23.08.20]
} 
This partly explains why even the few people who have seen the grammars of their languages are unable to read them. The excitement is reduced to keeping a copy and hoping that someday, after education in the foreign language, their children will come home and read the grammar. One way to overcome this problem is to organize literacy classes and assist those who attend them to learn to read and write their language. The first step would be for the grammar writer to develop basic literacy materials. The orthography should be kept as simple as possible (Bird 1999, Snider 2014). Afterwards, they will have to train a few people who can then become teachers of the language. All that requires time and funding, and must be done progressively according to the availability of resources.

\section{Conclusion}

The discussion in this paper has been largely about the need to write a grammar that is of value to linguists and other students of the language but especially of use to the community of speakers. This is important because the interest of a grammar writer should serve the people both now and in the future. The benefits of working on a language with the community and for the benefit of that community are enormous. The discussion offered here has shown that there are several issues to deal with in order to render grammars of indigenous languages useful to the community of speakers. Grammars can be put to such practical uses only if the linguists ensure that they are accessible to speakers of the language and that some speakers are trained to use them. Community sensitization, mobilization, training, etc. can be challenging tasks to perform. For an outsider interested in a given language, gaining access to the community and being accepted could take a short while but sensitizing and mobilizing people to join, running training programs and following up require more time and resources. As much as possible, these activities should be factored in during planning. Stenzel (2014: 289) states that community-based projects have "the potential to contribute to linguistic studies in unexpected ways and to produce data that is better in the sense of being richer and more complete", as well as resulting in outcomes better aligned with community goals.

A model that could work best is similar to that implemented by the SIL. It requires that the grammar writer should engage more with the community, allotting more time and resources to prepare literacy materials, follow up, and provide the community members with the training to read and write in their language. The grammar writers should ensure that the people obtain copies of the grammar and that the languages are introduced in the school system as media of instruction or, at least, as school subjects. 


\section{References}

Akumbu, P. W. 2018. "Babanki literacy classes and community-based language research". Insights from practices in community-based research: From theory to practice around the globe, ed. by S. T. Bischoff \& C. Jany. Berlin: Mouton de Gruyter. 266-279.

Akumbu, P. W. \& E. F. Chibaka. 2012. A pedagogic grammar of Babanki - a Grassfields language of Northwest Cameroon. Köln: Rüdiger Köppe Verlag.

Ameka, F. K. 2006. "Real descriptions: Reflections on native speaker and non-native speaker descriptions of a language". Catching grammar: The standing challenge of grammar writing, ed. by F. K. Ameka, A. Dench \& N. Evans. Berlin/New York: Mouton de Gruyter. 69-112.

Asohsi, M. 2015. Structural and typological approaches to Obang grammar: A Grassfields Bantu language of Cameroon. Köln: Rüdiger Köppe.

Atindogbe, G. G. 2013. A grammatical sketch of Mòkpè (Bakweri), Bantu A20. (African Study Monographs, Supplement 45).

Bird, S. 1999. "When marking tone reduces fluency: an orthography experiment in Cameroon". Language and Speech 42. 83-115.

Bischoff, S. T. \& C. Jany (eds.). 2018. Insights from practices in community-based research: From theory to practice around the globe. Berlin: Mouton de Gruyter.

Black, C. A. \& A. H. Black. 2012. "Grammars for the people, by the people, made easier using PAWS and XLingPaper", Electronic Grammaticography, ed. by S. Nordoff. (Language Documentation \& Conservation Special Publication 4). Honolulu: University of Hawaii Press. 103-128.

Bouba, A. 1995. "Quelles langues nationales dans les écoles?". Cameroon Tribune 20.06.1995. Yaoundé: SOPECAM.

Boutwell, R. L. 2010. A sketch grammar of the Nchane language. Yaoundé: SIL Cameroon.

Boutwell, R. L. 2014. A sketch grammar of the Mungong language. Yaoundé: SIL Cameroon. Cameron, D., E. Frazer, P. Harvey, M. B. H. Rampton \& K. Richardson. 1992. Researching language: Issues of power and method. New York: Routledge.

Chiatoh, B. A. \& P. W. Akumbu. 2014. "Enhancing English language studies in Cameroon: The mother tongue perspective". California Linguistic Notes 39(1). 23-47.

Chuo, G. K. \& S. Walter. 2011. The Kom experimental mother tongue education project report for 2011. Yaoundé: SIL Cameroon.

Crane, T. M., L. M. Hyman \& S. N. Tukumu. 2011. A Grammar of Nzadi [B.865], a Bantu language of the Democratic Republic of the Congo. Berkeley: University of California Press.

Czaykowska-Higgins, E. 2009. "Research models, community engagement, and linguistic fieldwork: Reflections on working within Canadian indigenous communities". Language Documentation \& Conservation 3(1). 15-50. 
Dobrin, L. 2008. "From linguistic elicitation to eliciting the linguist: Lessons in community empowerment from Melanesia". Language 84(2). 300-324.

Dobrin, L. \& J. Berson. 2011. "Speakers and language documentation". The Cambridge Handbook of Endangered Languages, ed. by P. K. Austin \& J. Sallabank. Cambridge: Cambridge University Press. 187-211.

Dobrin, L. \& J. Good. 2009. "Practical language development: Whose mission?". Language 85(3). 619-629.

Eberhard, D. M., G. F. Simons, \& C. D. Fennig (eds.). 2019. Ethnologue: Languages of the World, $22^{\text {nd }}$ edn. Dallas, Texas: SIL International. Online version: http://www.ethnologue.com [08.08.2020].

Fitzgerald, C. M. 2017. "Understanding language vitality and reclamation as resilience: A framework for language endangerment and "loss" (Commentary on Mufwene)". Language. e280-e297.

Fitzgerald, C. M. 2018. "Creating sustainable models of language documentation and revitalization". Insights from practices in community-based research: From theory to practice around the globe, ed. by S. T. Bischoff \& C. Jany. Berlin/Boston: Mouton de Gruyter. 94-111.

Genetti, C. \& R. Siemens. 2013. "Training as empowering social action: An ethical response to language endangerment". Responses to language endangerment. In honor of Mickey Noonan. New directions in language documentation and language revitalization, ed. by E. Mihas, B. Perley, G. Rei-Doval \& K. Wheatley. Amsterdam: John Benjamins. 59-77.

Grenoble, L. A. \& L. J. Whaley. 2005. "Review of language endangerment and language maintenance, and language death and language maintenance". Language 81. 965-974.

Grenoble, L. A. \& S. S. Whitecloud. 2014. "Conflicting goals, ideologies and beliefs in the field". Beliefs and ideologies in language endangerment, documentation, and revitalization, ed. by P. K. Austin \& J. Sallabank. (Proceedings of the British Academy 199). Oxford: Oxford University Press. 339-356.

Guérin, V. 2008. "Writing an endangered language". Language Documentation \& Conservation 2(1). 47-67.

Handman, C. 2009. "Language ideology and Christianization". Language 85(3). 635-639.

Hedinger, R. 2008. A grammar of Akoose, a northwest Bantu language. Dallas: SIL International \& University of Texas at Arlington.

Kadanya, J. L. 2006. "Writing grammars for the community". Studies in Language 30(2). 253-257.

Kafeteh, Z. 2018. Assessing mother tongue literacy in the Kom language. Unpublished MA thesis. University of Bamenda, Cameroon.

Keane, W. 2002. "Sincerity, 'modernity', and the Protestants". Cultural Anthropology 17. 65-92. 
Reflections on a community-based approach to writing...

Koops, R. 2009. A grammar of Kuteb, a Jukunoid language of East-Central Nigeria. Köln: Rüdiger Köppe Verlag.

Leonard, W. Y. \& E. Haynes. 2010. "Making 'collaboration' collaborative. An examination of perspectives that frame field research". Language Documentation and Conservation. 4. 268-293.

Lovegren, J. 2013. Mungbam grammar. Unpublished PhD dissertation. University at Buffalo, USA.

Lüpke, F. 2011. "Orthography development". The Cambridge handbook of endangered languages, ed. by P. K. Austin \& J. Sallabank. Cambridge: Cambridge University Press. 312-336.

McLean, G. L. 2014. A sketch grammar of the central Mfumte language. Yaoundé: SIL Cameroon.

Mithun, M. 2006. "Grammars and the community". Studies in Language 30(2). 281-306.

Mono Ndjana, H. 1981. Paradoxes: Essai sur les contradictions du sens commun. Yaoundé: Editions Objectif.

Mosel, U. 2006. "Grammaticography: The art and craft of writing grammar". Catching grammar: The standing challenge of grammar writing, ed. by F. K. Ameka, A. Dench \& N. Evans. Berlin/New York: Mouton de Gruyter. 41-68.

Nforbi, E. \& P. Ngum. 2009. Oku grammar. Dschang: Dschang University Press.

Nguendjio, E. G. 2014. A descriptive grammar of Bangwa. Köln: Rüdiger Köppe Verlag.

Noonan, M. 2007. "Grammar writing for a grammar-reading audience". Perspectives on grammar writing, ed. by P. E. Thomas \& W. J. David. Amsterdam/Philadelphia: John Benjamins. 113-126.

Ochocka, J. \& R. Janzen. 2014. "Breathing life into theory: Illustrations of community-based research hallmarks, functions, and phases". Gateways: International Journal of Community Research and Engagement 7. 18-33.

Payne, T. E. 2014. "Towards a balanced grammatical description". The Art and Practice of Grammar Writing, ed. by T. Nakayama \& K. Rice. (Language Documentation \& Conservation Special Publication 8). Honolulu: University of Hawaii Press. 91-108.

Pennycook, A. \& S. Makoni. 2005. "The modern mission: The language effects of Christianity". Journal of Language, Identity, and Education 4. 137-55.

Rehg, K. L. 2004. "Linguists, literacy, and the law of unintended consequences". Oceanic Linguistics 43(2). 498-518.

Rehg, K. L. 2014. "On the role and utility of grammars in language documentation and conservation". The Art and Practice of Grammar Writing, ed. by T. Nakayama \& K. Rice. (Language Documentation \& Conservation Special Publication 8). Honolulu: University of Hawaii Press. 53-68.

Rice, K. 2006. "A typology of good grammars". Studies in Language 30(2). 385-415. 
Rice, K. 2018. "Collaborative research: Visions and realities". Insights from practices in community-based research: From theory to practice around the globe, ed. by S. T. Bischoff \& C. Jany, Berlin: Mouton de Gruyter. 13-37.

Snider, K. 2014. "Orthography and phonological depth". Developing orthographies for unwritten languages, ed. by M. Cahill and K. Rice. Dallas: SIL International. 27-48.

Stenzel, K. 2014. "The pleasures and pitfalls of a 'participatory' documentation project: An experience in Northwestern Amazonia". Language Documentation \& Conservation 8. 287-306.

Tamanji, P. N. 2009. A descriptive grammar of Bafut. Köln: Rüdiger Köppe Verlag.

UNESCO. 2010. Education for all: Global monitoring report. Paris: UNESCO.

Viljoen, M. H. 2013. A grammatical description of the Buwal language. Unpublished PhD dissertation. La Trobe University, Australia.

Voll, R. 2017. A grammar of Mundabli, a Bantoid (Yemne-Kimbi) language of Cameroon. Unpublished PhD dissertation. University of Leiden, The Netherlands. 